\title{
How Students Use Their Cultural and Linguistic Knowledge to Transform Literacy Goals
}

\author{
Teresa Sosa and Catherine D. Bhathena \\ Indiana University Purdue University, Indianapolis (IUPUI)
}

\begin{abstract}
Author Note
Teresa Sosa, Indiana University School of Education, Indianapolis (IUPUI), 902 West New York Street, Indianapolis, IN 46202, 317-274-5882, tsosa@iupui.edu; Catherine D. Bhathena, Indiana University School of Education, Indianapolis (IUPUI), 902 West New York Street, Indianapolis, IN 46202, cdfuller@iupui.edu.
\end{abstract}

Black and Latinx youth frequently are asked to complete school tasks and activities without much focus on the knowledge and experiences they draw from to make sense of what they are being asked to do. Using culturally sustaining pedagogy as a framework, this work provides a clear example of the interactions, engagement, and learning that unfolded in a 9th grade English Language Arts classroom as broader goals of one lesson emerged through students sharing their lived experiences and concomitant understandings of the social world. This work provides a clear case for how to support the fullness of youths' identities as dynamic beings and provides evidence for how this does not detract from the goals of school activities, In fact, it enriches them and makes them meaningful.

\section{How Students Use their Cultural and Linguistic Knowledge to Transform Literacy Goals}

Black and Latinx youth are frequently asked to complete school activities without much focus on the knowledge and experiences they draw from to make sense of what they are being asked to do. This is despite the literature that emphasizes the importance of building on students' cultural, linguistic, and experiential knowledge (often encapsulated in the funds of knowledge concept) (Alim, 2011; Fecho \& Botzakis, 2007; González; Ladson-Billings, 1994; Kirkland, 2011; Moll \& Amanti, 2006;). When no connection is apparent between what students are asked to do and their experiences of the world, student responses to school tasks are often superficial. McCarthey (2001) describes this as "academic, perfunctory, and detached" (p. 134), leading to questions about whether the goals or objectives of the task (even when achieved), are the most beneficial. Using culturally sustaining pedagogy (Paris, 2012; Paris \& Alim, 2014) as a framework, this article aims to show how students in a $9^{\text {th }}$ grade English Language Arts (ELA) class shaped and reshaped one lesson activity and its related literacy practices and goals as they engaged in a discussion regarding the coming of age of a fictional 17year-old character named Lee. Our attempt here is to provide a clear example of the dynamic linguistic and cultural practices and interactions that unfolded as deeper 
goals of the lesson emerged through students sharing their lived experiences and concomitant understandings of the social world.

\section{School Realities for Students of Color}

What students of color bring to the classroom is often viewed in conflict with dominant forms of knowledge, social practices, and discourses. (Alim, 2011; Rex, 2006; Smitherman, 2004). Research has often critiqued the lack of classrooms as critical spaces where students' knowledge and questions, wonderings and interests, as well as their personal insights are central to learning (Alim, 2011; Dutro, 2008, 2010; Fecho \& Botzakis, 2007; Kirkland, 2011). Others have discussed the damaging effects of muting or shutting down student literacy practices and knowledge due to normative assumptions about how students should perform being a "good" or "successful" student. (Fine, 1987; Hall, 2011; Jabal \& Rivière, 2007; Leander, 2002).

Despite the consistent norm of excluding the know-how and lived histories of marginalized students to inform understanding, literacy research continues to emphasize the importance of including students' lived experiences in learning. Broadly speaking, in classrooms where the majority of students are students of color from working class backgrounds, students and families are often perceived as "somehow disorganized socially and deficient intellectually” (Moll, Amanti, Neff, \& Gonzalez, 1992, p. 134; Robinson, 2007). However, as Moll and his colleagues (1992, 2006) have demonstrated in decades of work, students' lived experiences in the form of "funds of knowledge" plays a crucial role in learning. Similarly, Yosso (2005) challenges this deficit view of students of color through a concept of "community cultural wealth" that is centered on communities of color and the wealth of "knowledge, skills, abilities and contacts possessed and utilized by [them] to survive and resist macro and micro-forms of oppression" (p. 77). It is these forms of oppression, demonstrated in schooling through the diminishing or ignoring of students' lived experiences, that can block students of color from making meaning of complex texts. Engaging students' funds of knowledge and cultural wealth in the classroom can have the opposite effect.

More specifically, researchers have emphasized how students' insights gained from their experiences help them situate the issues in texts at a social and structural level rather than a purely personal one (cf. Hall, 2011). They also help to apply creative ideas and make meaning of complicated concepts in texts (Brown, 2005). Also, these insights are central to engagement as students see themselves in the stories they read (Kirkland, 2011; Moje, Overby, Tysvaer, \& Morris, 2008). Students' insights also support new understandings of texts based on the cultural lenses and experiences students bring to texts (Fecho \& Botzakis, 2007). Overall, this work points to the significance of teaching literacy through "engaging students' cultures but also centralizing their lives" (Alim, 2011, p. 140).

Alim (2007) discusses the need to make an "ideological distinction between a curriculum that is based in the cultural-linguistic reality of the students, and one that...use[s] the language and culture of the students to teach them part of the 'acceptable' curricular canon" (p. 28). He argues that oftentimes, the cultural and linguistic resources that students bring to school are used as tricks to get them to the "standard English," always with the insistence of changing or "improving" what they come into schools with. He goes on to urge researchers to "shift the paradigm and turn to our students' abilities and experiences as the sources of knowledge and learning" (p. 28). Similarly, Kirkland (2008) highlights the need "to situate English Language Arts (ELA) in the lives and realities of today's youth" (p. 69). He envisions this as 
expanding what we view as literacy, texts, and experiences, as well as valuing aspects that come out of the silenced experiences of marginalized groups. A pedagogy that allows us to do that is culturally sustaining pedagogy, to which we turn next.

\section{Theoretical Framework}

Our work centers students' experiences and cultural and linguistic knowledge in learning and teaching. As such, we as scholars and teachers view learning as a part of everyday social practice that is mediated socially, relationally, and culturally (Gutiérrez \& Rogoff, 2003). Therefore, our framework aligns with literature related to culturally sustaining approaches to pedagogy (Paris, 2012; Paris \& Alim, 2014).

Understanding culturally sustaining approaches to pedagogy begins with understanding culturally responsive approaches. A culturally responsive approach (Gay, 2000; Ladson-Billings, 1994, 1995) to teaching places value on students' insights, language, and cultural practices, all with the understanding that culture is dynamic and therefore mindful of not reifying assumptions of language and ways of being as the ownership by particular groups of people categorized by race and /or ethnicity (Alim, 2011; Paris, 2012). For example, in a study by Irizarry (2007) that analyzed practices identified as culturally responsive by Latinx students in a vocational high school history class, he indicated how Latinx students noted the importance of being able to bring into the classroom the practice of "how we speak in our neighborhoods." Irizarry writes that the hybrid language practice in students' neighborhoods in this case was Black English, and that "static understandings of Latino culture would not account for the ways that Ebonics, and not Spanish or variations of the Spanish language, was used as a bridge to gaining Standard English proficiency” (p. 25).

This approach also focuses on understandings that support students to critique injustices, oppression, and other social-political issues (Gay, 2000). For example, it is this emphasis that is at the heart of work that looks at how Indigenous youth reclaim their language through counter-narratives (McCarty, Romero, \& Zepeda, 2006). It is also centered in projects such as the Social Justice Education Project (SJEP) (Cammarota, 2007), which served as an alternative social science curriculum for high school Latinx students placed in alternative programs due to their "at risk" status. SJEP provided challenging, socially-relevant coursework "contextualized in the social life and experiences of students" (p. 90).

Culturally sustaining pedagogy builds from and expands pedagogical understandings centralized within culturally responsive approach. Culturally sustaining pedagogy, according to Paris (2012), "seeks to perpetuate or foster-to sustain-linguistic, literate, and cultural pluralism as part of the democratic project of schooling” (p. 95). Both Paris (2012) and Alim (Paris \& Alim, 2014) emphasize that linguistic and cultural ways of being are ever-changing, and thus, are much more than "traditions." Their work highlights the complex and shifting relationships among race, culture, and language that "belie easy categorizations of what it means to be Black or Brown" (Paris \& Alim, 2014, p. 95) and emphasize fluid identities. Moving away from essentialized race/ethnic identities requires the acknowledgement that hybrid identities are achieved through a diversity of experiences and through relationships with others (Irizarry, 2007), or what Gutiérrez and Rogoff (2003) refer to as repertoires of practice rather than as static and inherent traits or abilities. As Gutiérrez (DiGiacomo \& Gutiérrez, 2017) asserts “[t]aking repertoires of practice approach requires a fundamental view of culture not as a fixed collection of traits or characteristics, but as a fluid constellation of experiences within a particular community or set of shared practices 
and histories" (p. 53), in other words, the "linguistic, literate, and cultural pluralism" that Paris describes (2012, p. 95). These pluralisms include the ways in which pedagogical practices value, cultivate, and expand student repertoires of practice (Gutiérrez, Larson, \& Kreuter, 1995; Lee, 2007; Paris, 2012) and centralize student linguistic, cultural, and language expertise (Campano, 2007; Dyson 2008; Moll, 1992). When students' experiences and cultural and linguistic knowledge is thus centered, students claim the right to set and expand learning goals and utilize their lived experiences to accomplish said goals.

The distinction between culturally relevant and culturally sustaining pedagogies exists in why students' lived experienes and cultural and linguistic expertise is used in the classroom. When using culturally relevant pedagogy, teachers focus attention on the use of language and discourse in the classroom and use "indigenous languages and cultural practices that preserved, valued, and honored their home and community environments as a scaffold toward academic learning" (Thomas, 2013, p. 1). In other words, culturally relevant pedagogy recognizes and honors the experience and expertise of students and incorporates it into classroom practices in order to guide students towards accessing the dominant American language, discourse, culture, and norms, and in turn, equity and academic success. This success, as defined in current U.S. educational policy, assumes a continued mono-cultural dominant U.S. society and culture (Alim \& Paris, 2014).

Culturally sustaining pedagogy, while recognizing the importance of all students having access to dominant discourse and culture, takes a pluralistic approach to guiding students to equity and academic success in a society that's demographically becoming majority multicultural and multilingual. This change requires schooling practices that promote "linguistic and cultural flexibility [as] an instrumental purpose for both students of color and White students [as] multilingualism and multiculturalism are increasingly linked to access and power in U.S. and global contexts" (Paris and Alim, 2014, p. 87). Thus, when engaging in culturally sustaining pedagogy, as opposed to culturally relevant pedagogy, teachers use student lived experiences and assets, their cultures, as the basis of all instruction and not only as a bridge to dominant American English discourse and culture. So, this approach to pedagogy considers maintaining the many cultures and languages of students as an integral part of students' achievement of equity and academic success.

Like the literature discussed, this article describes an ELA lesson that embodies culturally sustaining pedagogies and adds to the recent literature that emphasizes students' lived experiences. The insights cultivated through such experiences, along with hybrid identities and repertoires of practice, are central to both curriculum and learning. In this paper, we explore that centrality by examining how students' discussion contributions expanded the goals of the lesson. These goals broadened from practice of a disciplinary skill and making literary arguments to an opportunity for students to connect with peers through sharing of their culture, language, history, and values-all as a way to assess a fictional character's dilemma.

\section{Data Sources and Analytic Methods}

The study was conducted in the context of a larger research and development effort ${ }^{1}$ focused on supporting adolescent students in acquiring the knowledge and skills

\footnotetext{
The work reported here is part of a research project supported by the Institute of Education Sciences, U.S. Department of Education, through Grant R305F100007 to University of Illinois at Chicago. The opinions expressed are those of the authors and do not represent views of the Institute or the U.S. Department of Education.
} 
needed to engage in literary analysis and argumentation. Emphasis was given to providing students opportunities to take on significant roles in developing these skills through disciplinary discussions. Ms. Brett volunteered to be part of the project and one class period was chosen for implementation of the curricular unit.

Data for this work comes from a nine-week intervention that was documented through video recordings and field notes. The documentation focused on how students applied the skills and concepts being implemented. A major focus on outcomes was through whole class discussions as students talked about their understandings of themes, form, and function of language and connected such understandings to their awareness of the social world. Along with the teacher, the first author of this paper and a graduate student were present every day during the implementation. The first author co-taught most lessons over the nine weeks and the graduate student took field notes and videotaped the classroom lessons.

We must note that this classroom discussion was the first of many over the nine-week intervention unit that supported students in building interpretations and understandings based on their experiences and linguistic and cultural practices. Because this work aims to more closely analyze how discussions take shape as this happens, we focus here on one discussion. The 37-minute discussion took place close to the beginning of the unit, around week three. In this discussion, 14 out of 18 or $78 \%$ of students present participated in the discussion.

\section{Methodological Orientation}

The method we engaged in for this study is grounded in Bloome's (Bloome, Carter, Christian, Otto, \& Shuart-Faris, 2005) discourse analysis (DA) approach for classroom interactions. Bloome refers to this type of DA as a "microethnographic approach" because it combines a variety of ethnographic and linguistic methodologies focused on language, literacy, and culture (p. xv). We used microethnography to analyze interactions and talk within the context of a single discussion in the classroom.

\section{Analysis}

The two authors began from different experiences with the data. The first author was part of the intervention and worked closely with the teacher and students (more will be said on her role and positionality in the next section). The second author was invited by the first author to participate in analyzing this classroom discussion and coauthoring the paper. She was not involved in the larger research project, thereby bringing an outside perspective to the analysis and discussion. In addition to the outside perspective, she also brings 12 years of teaching experience in ethnically and economically diverse spaces. As a white, middle class education scholar, the second author has focused her doctoral studies and research on teachers of culturally and linguistically diverse students in mainstream classrooms. As a teacher, researcher, and participant within many learning and cultural communities, the second author attempts to enact emancipatory and humanizing practices informed by her understanding of the historical tensions between the primarily white, female, middle class teaching force and students of color and culturally and linguistically diverse students, as well as her own understanding of critical whiteness studies (Delgado \& Stefancic, 1997).

We adapted an analytical tool from Bloome's et al (2005) discourse analysis for looking at classroom literacy events. This is a two-level description of interaction that allows for analaysis of the conversational function of each message unit at each level. The research questions, classroom context, and the first author's familiaritiy with this 
classroom guided the adaptation. Bloome and his colleagues attest that literacy events must be analyzed at a deeper level beyond the structure of the discussion; he calls this the "underlying argument level" (p. 68). This dimension allows one to highlight aspects of conversations that might not be apparent and the recognition that students are acting on the event and changing it. The dimensions that need to be considered as part of analysis include the cultural and literacy practices brought into the event, "what happens in the event (how people act and react toward each other), the particularities of the event... and what social significance and consequence the people in the event assign to the event as a whole and to what happens in the event" (p. 56). Using this level of analysis allowed us to see the ways in which students adapted the lesson along with the recognition that they are actively expanding the goals of the lesson.

Once we analyzed the discussion at the two-level description of interaction, we then looked to the scholarship related to funds of knowledge and culturally sustaining pedagogies to guide further analysis. The process for this part of the analysis is based on thematic analysis (Smith \& Osborne, 2008) or what Saldaña (2013) calls "themeing the data." The following themes were developed based on the literature and framework: students able to see themselves in the text; meaningful inquiry of human experience; build understandings from lived experiences; and community-shared nonstatic practices and beliefs.

We analyzed the discussion at the underlying level separately and then engaged in collaborative discussions. Through recursive processes of analysis, we negotiated our understandings of the dimensions of the discussion and came to understand the aspects of conversation used to expand the goals of the activity. Together, we further analyzed the discussion based on the thematic codes noted above from the literature related to funds of knowledge and culturally sustaining pedagogy.

\section{Context of Classroom Lesson}

The study took place at Fairfield High School. Fairfield is a military academy with less than 400 students that is part of a large school district located in a working-class neighborhood in a large Midwestern city. The ELA class was comprised of 19 students, 12 boys, seven girls; nine students are black, eight Latinx, and two white. Ms. Brett is white with two years of experience (at the time of the study) as a high school ELA teacher.

The first author of this paper was a researcher with the larger project. Her role in the classroom was as teacher to students (teaching many lessons, co-teaching many others with Ms. Brett) and mentor/coach to Ms. Brett. Throughout the nine weeks of the intervention, the first author debriefed with Ms. Brett and planned ongoing instruction based on the goals of the intervention and what was happening in the classroom.

Ms. Brett was a very energic teacher who was liked by students. Because Ms. Brett and the first author worked well together, and students knew that the first author was there to mentor and support their teacher, they were willing to accept her as their teacher also. This created a space where the specific practices of the intervention were rooted in discussions that centered students' understandings, insights, and expertise. This stable context, we believe, led to the many honest, critical, and open discussions that took place during the intervention, starting with the discussion analyzed here.

The first author is a former high school English teacher with seven years of experience in a large public-school system. As a Latina scholar, the first author's experiences in what Solórzano and Yosso (2002) call "multiplicity of racialized oppression" (p. 38) as 
well as her resistance against such oppression informs and frames her pedagogy and research. In both pedagogy and research, the first author situates herself in "communion with a collective experience marked by marginalization, oppression, or resistance” (Delgado Bernal, Burciaga, \& Carmona, 2012, p. 363) That is, she approaches both the pedagogical and the research aspects of this and all her work from a place of collective experience. Her participation as a teacher, researcher, classroom member, and witness to discussions is an intentional stance that connects more closely her positionality, identities, and methodological and analytical lenses from which she wishes to attend to assets and strengths of students of color in classrooms. As stated previously, the second author was not a participant in the classroom context.

The discussion that is the focus of this work took place about three weeks into the intervention. At that time, students were exploring coming of age as a theme and working on developing criteria by which to evaluate this theme. Coming of age is an archetypal theme in many literary works. It captures crucial experiences that characterize the transition from adolescence toward the maturity of adulthood (Lee, 2007). In this lesson, the class was exploring criteria for coming of age based on given scenarios of youth and their actions and reactions to particular events. These scenarios were developed by researchers as part of the intervention. Below is the scenario handed out to students and the questions posed for discussion.

Lee has lived with his grandmother since he was seven and his mother was unable to care for him. Although his mother lives in a neighboring state, she has never come to visit Lee. Every year at New Year's and on his birthday, his mother calls Lee, and every year she tells Lee that she plans to come to visit in the next month or two. Every year, Lee believes his mother. On his sixteenth birthday, Lee gets his regular call from his mother, who again tells him that she will be coming to visit soon. Lee starts shaking his head as his mother talks, and then begins to scream at her on the phone, yelling and crying, telling his mother he doesn't believe her anymore, and that he hates her. Lee throws the phone across the room and breaks it. He never speaks to his mother again.

Has Lee "come of age”? Why or why not?

We present three episodes of the classroom interactions to demonstrate how new investment and learning occurred over the span of the 37-mintue discussion ${ }^{2}$. These also illustrate how students took up and made sense of the complex arguments peers made in their moment-to-moment classroom interaction. The focus on this joint construction of discussion relies both on what students find to be significant within the scenario and how students use their insights of the social world to determine Lee as having come of age or not.

In the first episode, students argued for or against the belief that Lee had come of age based on moral responsibility. While some students believed it was the mother's obligation to take care of Lee, not lie to him, and be in charge of rescheduling planned visits, others argued that Lee, as a son, needed to have respect for his mother. His ways of reacting indicated not only disrespect but immaturity, characteristics contrary to coming of age. In the second episode, students more explicitly drew from their understandings of the social world based on cultural and linguistic knowledge. It is here that students poignantly discussed their own lived experiences of abandonment and

2 Episodes were defined as classroom activity during the instructional period that centered on a specific goal or topic (Bloome, Carter, Christian, Otto, \& Shuart-Faris, 2005). 
used these as evidence for how they saw Lee. The third episode moved into problematizing students lived histories but also characterizing students as having come of age themselves and one student declaring his own repositioning.

\section{Episode 1: Moral obligations}

The discussion on this day began with four students commenting how Lee had indeed come of age because he had "stepped up" by no longer believing the mother's promises and by realizing how he felt about the situation. Meanwhile, Abe, who had been trying to enter the conversation, repeated, to much classroom laughter, "I would like to disagree with all of them." When Abe finally did get to speak, he noted the following.

1.1 Abe: I would like to disagree with all of them. He never even asked his mother why she hadn't come to see him, maybe she had been working and had hard times herself and she hasn't really had the time to come see him. So, you know, maybe she hasn't had time so you can't get mad at her.

Here, Abe challenged the general initial consensus about Lee. Specifically, he moved away from a focus on Lee's emotions and related actions as valid evidence for coming of age. Instead, Abe constructed a social reality as a way to more clearly situate the issue at hand. He suggested two real issues for why the mother has not seen Lee: 1) she has been working and therefore has not had the time; and 2) she may be going through hard times. In other words, Abe provided aspects of the social world of low-income families. For example, in what Abe suggested, the mother has to work long hours, a reality that those who experience material poverty often face. And, even when individuals work long hours, they oftentimes continue to face financial difficulty. This is important because Abe described real conditions that parents who are working class often face.

As the discussion continued, Len joined Abe in disagreeing that Lee had come of age, emphasizing Lee's conduct and the issue of hard times.

1.2 Len: I agree with Abe because. . like Abe said she might be working and stuff like that, like she might be in hard times. I would like to add on to what he said. I think like he threw a temper tantrum; he shouldn't have disrespected his mother like that.

1.3 Abe: Cause that's his mama.

1.4 Len: Yeah, that's his mama, my mama would have (inaudible). But he shouldn't have did that to her and he threw the phone and broke it and all that. I know young kids more respectful than that; who wouldn't even do nothing like that to their mama.

In this exchange, Len described Lee as impertinent and immature as indicated by his statement in line 1.4, "I know young kids more respectful than that," along with comparing Lee's actions to throwing a temper tantrum, a term usually reserved for very young children (line 1.2). Len's and Abe's insistence that the way Lee addressed his mother is wrong because "That's his mama," speaks to the understanding that all literacy practices "are almost always fully integrated with and interwoven into the very texture of wider practices that involve talk interaction, values, and beliefs" (Gee, 2015, p. 49). In this case, Len's statements emphasized the moral obligations of a son regarding his conduct towards his mother, an authority figure.

Ryan then spoke up in support of Len and Abe's opinion.

1.5 Ryan: In this passage, he did not come of age, I believe this because what we have so far on the board [referring to and reading a specific coming of age criteria] 
"show respect to others and to yourself." If he is going to handle the situation where he doesn't want to talk to her anymore, he can tell her in a respectful manner. Other words that we can put up there [referring to the criteria on the board] is patience. And if he came of age, the story could have been the same, but he could have handled the situation differently. He could have told his mother, "Mom, I don’t believe you anymore. I actually, I honestly don’t care."

Ryan focused here on the lack of respect that he saw from Lee in the passage. Ryan seemed to understand respect as essential to interactions, particularly between youth and adults. This is evidenced in his suggestion that Lee "could have handled the situation differently" and his rephrasing of Lee's response. Interestingly, Ryan also suggested a new criterion to consider, the virtue of "patience." Because JROTC is a big part of his identities, the values emphasized in this organization, like respect and patience, are reflected in his perception of Lee.

Up to this point, students constructed Lee's actions and relationship with his mother based on their social understandings of the real world. They used the same insights they use to understand people in their daily lives to make sense of characters and situations in texts (Hamel \& Smith, 1998). Students were also clearly drawing from social, cultural, and literacy practices related to family and programs, such as JROTC. For Len, the family practices he valued account for how he considered the situation. He explicitly applied his cultural expertise of mother-child interactions when he began to suggest what would happen to him if he would ever attempt to interact with his mother in the way Lee did. He further did so in in line 1.4, when he made it clear that acting in this way was a violation of how to act towards one's own mother. For Ryan, the emphasis on character education, especially respect, from the JROTC program seemed to influence his stance in this contribution and in later ones. After more back and forth, including disagreement by Wes, Ema, and Ana, Fran's contribution opened up new ways of providing insights based in embodied experience.

\section{Episode 2: Embodied experience}

When Fran entered the conversation, she explicitly negated the suggestion previously made by her peers. Fran's contribution (line 2.1) is in response to Ana and Ema's argument that Lee should not be expected to have patience and respect for his mother after he had been waiting 10 long years for her to show up.

2.1 Fran: I would like say that Lee has not come of age because I have been in that situation for about my whole life, and the fact that I was adopted and everything and my god mom said, 'Oh, one day you will see her, I know you need to see her.' But for the past 15 years of my life I never got any calls from her, I've never seen a picture of her, I've never, I don't even know anything about her, I don't even know her first name. So, it's like, if I ever saw her, I don't even know what I would do. But I know that I wouldn't act like Lee, I would never say 'I hate you, why would you ever leave me' cause I understand that maybe it was something that she wasn't able to do, maybe it was something that she couldn't do for me and that I want a life with my mom [Wes goes to Fran and hugs her] maybe it wasn't the right time to come to see me or me to see her.

Fran's lived experience, although similar to that of Lee, provided Fran with a different understanding. Fran's personal history, in many ways, encompasses more loss than Lee's. However, Fran was clear that she would never demand what Lee asked from his mother. Fran's understanding of her mother's decision to give her up for adoption and 
not look for her, rests on insight from her own history of abandonment. Through her loss, she recognized that her mother had valid reasons for not being able to take care of her.

Fran's telling opened up the classroom space for students to tell their stories in ways that allowed them to constitute themselves in much more humanistic ways than classrooms usually allow. Here, Fran shared her lived experience as a way to provide testimony that one can have similar experiences to those of Lee's, but the reactions can be quite different. She made this clear when she stated that she would never say 'I hate you, why would you ever leave me' to her mother. Her insights from her own sense of abandonment helped her realize that what she wants is something her mother was not able to provide. This understanding is similar to Abe's with regards to Lee's mother in line 1.1. Both Abe and Fran understand that mothers who are struggling (financially and in other ways) often find it difficult to take care of their children. Fran's point that she would never say to her mother that she hates her also echoes the point made by Len earlier, that respect for one's mother should never be violated (line 1.4). The belief that children should never treat their mother disrespectfully is a cultural practice that guides values and beliefs about parent-child interactions.

Both Fran and Abe bring keen insights to what happens when a mother (or family) financially struggles, when a parent has to be absent from a child's life, and when the child lives with the repercussions of such situations. According to Strauss (1978), "The social world perspective reminds us that their participants may bring active perception and judgment as well as a great deal of knowledge and even study to the events of their social worlds" (p. 126). It is possible that Abe may know people in his life that have lived through this this type of experience. For Fran, her experience is personal.

But here, it must be emphasized that these students are not just knowledgeable and maybe even experienced in realities of material poverty; they also draw from their identities and experiences as members of communities who struggle with severe social constraints based on the institutionally-legitimized, deficit understandings of black and brown children and their families (Anyon, 1980; Heath, 1983; Valenzuela, 1999). That is, race and social location are intertwined and although it is not explicitly addressed by students here, we must acknowledge that all students sharing, except for Ema, are students of color from low-income communities.

It is Ema who responded to Fran with her own story to support the belief that Lee has come of age. Ema addressed Fran directly.

2.2 Ema: So, you said you were adopted; I know how that feels, my parents left me when I was little; my grandparents raised me. My dad has tried to call me and every time he breaks that promise, every time. In my opinion, I feel like he [Lee] did come of age. He actually stood up to somebody, even though it's his mom, yes, he was disrespectful, but he did the right thing, because she kept promising and promising, but she never follows through with that promise. And it does get to you, at one point you will get mad enough and say some disrespectful things.

Similar to the first excerpts above, both Fran and Ema focused on different aspects of their situation and Lee's as they made their case. Fran focused on how there must be reasons for her mother not reaching out to her, while Ema justified how Lee reacted because of all the broken promises. In what seems more like an intense conversation 
among friends than a typical academic classroom discussion, Ema and Fran went back and forth for several turns, while students intently listened and waited to provide support for one view or the other.

The conversation continued, rooted in student lived realities, for 11 minutes. During this time, Gil shared how he never met his dad and watched his mother "work her butt off" to raise him. It is also here that Luz shared her experience and then Wes entered the conversation.

2.3 Luz: I agree with Ema and Ana, you have parents and should be grateful but sometimes parents don't treat you (inaudible) or don't have much time to spend with you, even though you appreciate, I mean, you understand. In my point of view, I finally found the courage to stand up to my dad to tell him how I feel and everything, cause I'm really scared of him. But I finally told him how I feel, and I told him I was tired (inaudible), tired of everything, and I couldn't cry because everything was gone and I finally stood up to him in the end. And once I stood up to him and everything, he understood, and after that we've been getting along so I agree with Ema's point of view and Ana's.

2.4 [Students clapping]

2.5 Wes: I would like to agree with Ema, Fran, and Luz, cause when I was younger I never had my daddy or mamma. Like right now I am living with my daddy's exgirlfriend. Like Luz, I told my daddy and mama how I feel about everything. I still talk to him and see him, but not like a father and son; I see him for like only five minutes. After I told him how I feel, I just started (inaudible) coming through for everything

2.6 T: So, your talking to your dad was like a coming of age moment for you?

2.7 Wes: It was. Yeah, it made me realize that I have male figures in my life but I really want my dad to be there for me, but it seems like (inaudible). All I gotta do is try not to think about it; try to get over it.

There are two important aspects that emerged during this part of the discussion. The first is the move from simply agreeing about Lee's maturity to acknowledgment of difficult situations among peers. The second is the ways in which students reacted and heard their peers differently as they shared their personal experiences.

When Luz entered the conversation in Line 2.3, everyone took notice because Luz had not participated in discussions up to this point. In fact, this was the only time she contributed to discussions during the nine weeks. Luz addressed the fact that sometimes parents do not treat you fairly and that makes it especially difficult for someone to feel grateful and not lash out. Here, Luz brought in the understanding, although implicit, that it may be easier to lash out than to confront a parent. She emphasized finding courage to tell her father how she felt even though she was afraid of him. Wes did something very similar.

In line 2.5, Wes began by acknowledging agreement with Fran, Ema, and Luz. Fran and Ema had opposing views of Lee's coming of age, while Luz did not state how she saw Lee. Thus, Wes, like Luz, rather than agreeing about others' opinion regarding Lee, conceded how difficult abandonment and addressing it can be. Wes used this moment as a space to share not only his experiences but his emotions and what he learned. Luz and Wes, along with Ema, Fran, and Gil, exemplified their linguistic capital (Yosso, 2005) that is, their social and communication skills to tell their stories and insights related to pain, fear, and loss. Through their lived experiences and wisdom garnered from their circumstances, these students gained an important perspective of their 
social world that helped them courageously address their needs and move from places of resentment to understanding of their parents' lived realities.

As students listened to their peers' personal strife, they indicated acknowledgement and caring in ways that schools do not often value. Among them was the ability to publicly recognize someone's pain. For example, as Fran told her story (line 2.1), Wes went over to her and hugged her. Another example is how students recognized Luz's courage through their clapping as she recounted standing up to her father (Line 2.3). Students also clapped when Wes provided his final statement (line 3.2, below). Other indications of compassion can be seen in the way several students addressed what was said. For example, Ema told Fran in line 2.2 that she knew how Fran felt, as she connected her own story of being left by her parents to Fran's story of being raised by her grandmother. Also, several students used phrases such as, "I hear what you're saying," and even when proposing a differing view, like in the case of Ryan, he stated "I hear everyone on the other side," in line 3.1 (below) even as he tried to gain support for his own perspective on the scenario.

Students' public forms of acknowledgement and comments of relatedness created a space for visible empathy. This reaction to such vulnerable ways to be in the classroom may have moved other students to share their story. As "creators and active subjects of their own stories," (Jones, 2004) they shared similar stories of loss and pain. Students felt safe being vulnerable and expanding their identities beyond students and peers in the classroom. In this accepting space, Fran related how parents leaving "makes you feel like they never cared at all"; Ema described her experience as making her "feel like you are a big waste of time, you shouldn't have even been there in the first place." And Gil shared how his father's lack of return felt "like he don't care anymore." In this moment, student experiences, as embodied stories, became central to learning, to making sense of the text and achieving the academic goal set at the beginning of the lesson, but also to making sense of shared experiences that have shaped their identities.

\section{Episode 3: Student coming of age narratives.}

Immediately after the exchange concerning how it feels to be left by your parents, Ryan entered back into the conversation, referring to a point made by Abe almost 5 minutes earlier, suggesting Ryan had been closely following the conversation.

3.1 Ryan: I would like to agree with Abe, I hear everyone on the other side that said that Lee had come of age, that he just snaps, and just goes off on his mom and there's emotion. I understand about how he feels but when I relate it what we have on the board as far as maturity and then relate it to the other scenarios, actually it looks like he didn't come of age at all. The only thing from up there is knowing right from wrong, he probably did do the right thing, but he didn't do it mature; he wasn't showing respect. He didn't show respect to his mom or to himself; he wasn't very wise about it. Like the way Luz said, she actually went to talk to her father and after that they actually got along once they talked it out.

When Ryan stated that he was relating Lee's case to the other "scenarios," he seemed to be referring to the personal experiences shared by his peers. His explanation showcased how if one is mature, then one has self-control and does not "snap," or "goes off on his mom." In this way, Ryan positioned his peers' actions as examples of how these types of lived experiences can be handled maturely. He specifically pointed out how Luz handled her difficult relationship, thereby positioning his peers as having come of age themselves. Ryan combined his previous criteria with new evidence shared by the 
students to support his initial point line 1.5): to come of age means dealing with difficulty in a respectful manner. In a way, this moment contains a specific example of how the goals of the lesson were broadened by considering students' stories equally important to the scenario and criteria.

Towards the end of the conversation, Wes reentered the conversation.

3.2 Wes: I would like to reposition myself, I kind of disagree with the whole case scenario; I do believe he didn't mature (inaudible) cause as other people said, because if he was mature he would have learned some control and talk to his ma, like "Ma, how come you've been doing this to me? I really want to see you; you hurt my feelings" and stuff, or he would have learned to move on, self-discipline and learn to just move on, take care of himself.

3.3 [students clapping]

3.4 Researcher: Did you change your mind based on what was discussed?

3.5 Wes: Yeah

Wes was the only student who changed his view about whether or not Lee had come of age during the discussion. His comment indicates students created a space to reflect on their lives and develop criteria to recognize a coming of age experience. Also, they opened up a space where they felt free to change their views. Wes' example in line 3.2 suggests showing vulnerability with parents is indicative of maturity while disrespect is not.

Wes' change in point of view is also from blame (of the mother) to action (on the part of Lee). He moved Lee from victim to someone with agency, who should "learn to move on and take care of himself." The agency he provided to Lee is the same one he took on in his sharing about how he needed to try not to think about his father and just "get over it." Wes' lived experience and those of his peers who shared provided an epistemic orientation to difficult parent-child relationships. These experiences helped all class members see more fully the circumstances of the character, Lee, and of their peers, and then to imagine different possibilities for dealing with difficulty.

Additionally, throughout the discussion, students' contributions to the conversation demonstrated how students move fluidly between their identities as students, peers, and children living in families experiencing material poverty and the impacts of that poverty on parent-child relationships. Each contribution to the conversation included students sharing those identities in their own voice, using their agency to choose what they share (or don't). Students' contributions positioned them as having come of age, mature, and respectful in parent-child interactions. For example, Wes's contributions are particularly indicative of such fluid identities. In his first contribution, Wes agreed with students who said Lee had come of age and shared some personal family conflict he experienced. Through his sharing, Wes appeared as someone who can tell when he is being lied to and able to cut off ties with family. But as the discussion continued, Lee was characterized by other peers as child-like (throwing a temper tantrum), disrespectful to his mother, and not willing to contemplate financial or emotional situations as reasons for his mother's inability to see him. Students who supported Lee's actions and saw him as coming of age run the risk of also being identified as childish, disrespectful, and with an inability to understand others' situations. Once Lee's characterization as immature and disrespectful was established, Wes came back into the conversation and explicitly repositioned himself, thereby aligning himself with those who are mature or have come of age by finding ways to respectfully talk to their parents and exerting self-control. Outside of his verbal contributions, Wes's actions, such as 
clapping and hugging Fran, characterized him as an empathetic peer. Given the broader story and language used for signaling Wes's social and cultural identity (c.f., Gee, 1999), it is important to recognize the identities Wes chose to enact in this discussion and how they contrasted with how he was identified by his teacher outside of this discussion. That is, in other situations, Wes, as a young black male, was socially identified as, problematically challenging and "naturally" academically unambitious (Sosa, 2017).

Ryan's final contribution to the discussion was a question directed at the teacher and researcher as they were wrapping up class, "do you think he has come of age or not?" This question intentionally brought the teacher and researcher into the discussion to share their opinion, which they had not done to this point. It may be that Ryan was looking for a final answer to this question because that is how traditional classroom discussions work-typically, there is a final answer and it usually comes from the teacher as authority in the room-or it may very well be an example of shifting from a sense of knowledge as a product (some have more) to one of knowledge as process (the interactions, connections, and insights one shares). In the latter sense, teachers do not lead or dictate discussion nor do they position themselves as having more knowledge, but are certainly part of conversations because they too, have insights to share based on their own experiences (Bean \& Moni, 2003; Ladson-Billings, 1995). In response to Ryan's question, the researcher stated, "Maybe the way he did it wasn't the best way. Sometimes we lash out; sometimes, we can't help it. I might agree with you, but I can also see how we get caught up in our emotions." Ms. Brett then added, "I agree; he made a mature decision but he may not have done it in a mature way." Both teacher and researcher affirmed what the personal contributions by the students indicated: decisions around difficult parent-child relationships are complex as they are based on emotions, values, and beliefs.

\section{Discussion and Implications}

In this lesson, the goal was for students to practice the use of criteria for building literary arguments. This part of the lesson was expected to take about 20 minutes after which the criteria would be used with other scenarios in an effort to highlight how one determines whether characters have come of age. What students constructed, instead, was a discussion that lasted approximately 40 minutes in which they purposefully deliberated on the question, "has Lee come of age?" Because students were supported in addressing this question by bringing in their lived histories and cultural and linguistic knowledge, this discussion embodied a culturally sustaining approach.

The focus on students, rather than the technical aspects of the lesson (e.g., list five criteria, use with other scenarios, take 20 minutes, etc.) reinforces the understanding that students needed the time and openness to truly consider Lee's situation by looking not only at the criteria established in a previous lesson, but also by voicing their own experiences as resources to making assertions about Lee's circumstances. In this way, students were able to draw from their identities beyond that of students, from who they are as part of child-parent relationships, as members of JROTC, and as youth shaped by experiences of loss. Students were also able to listen and connect with peers in a much less detached way than often allowed in schools. They enacted different ways of acknowledging their peers' testimony, including through statements such as "I get what you are saying," and "I was also abandoned when I was two," as well as physical gestures like hugs and clapping. 
Students' lived histories provided much needed context to the scenario and in doing so, they were able to get at questions regarding human experiences, what it means to be hurt, to be abandoned, and what it means to forgive. Such questions emphasize moral, and social values and commitments one brings to making sense of stories and characters. Supporting students to voice their experiences and gained insights provides a different understanding of what learning can look like in school. It also provides a clear case for how to support the fullness of youths' identities as dynamic beings and provides evidence for how this does not detract from the goals of school activities. In fact, it makes them meaningful.

More examples like this of classrooms are necessary to highlight in future research as there are a multitude of ways in which centering student wisdom, practices, and identities can be expanded and supported. More research on classroom interactions would begin to get at understandings of how spaces that embody culturally sustaining practices are created and how they shape and reshape learning in that space for students of color. Critically, research needs to begin documenting just what engagement for students of color looks like and how this can help move us past a normative white lens of what should happen in schools. Examining these spaces can also help us to question our assumptions that lead us to focus on the lesson and related goals, versus students' holistic development and our investment in who they are.

For teaching practice, this work suggests that how students are supported in engaging in classrooms is closely connected to how we continue to challenge the historical understandings of both schooling and the treatment of students of color. This points to the importance of space for students to share their stories and talk about their beliefs and understandings, grounded in their lived experiences. Alim (2011) and others (e.g., Noguera, 2003) talk about classrooms as spaces where students are able to share their insights about the social world as well as their personal and painful experiences, their struggles and frustrations, their fears; a place to be safe and vulnerable. Furthermore, Dutro and Zenkov (2008) argue that students in urban contexts, particularly those living in poverty, need spaces to tell their own stories "in ways that can challenge the deficit perspectives through which others too often interpret their lives" (p. 174).

More current work also provides important insights into how to engage students in ELA classrooms in ways that challenge traditional ways of doing curriculum. For example, looking at how teachers navigate conversations about race emerging from literature units, that while necessary, are often fraught with conflict (Thomas, 2015). And supporting students in accessing the practices and skills that the discipline requires through approaches that are not simply technical and detached, but open to participatory and transformative paths that highlight a social justice orientation (Dyches \& Sams, 2018). We must continue to add to this work in order to provide teachers and pre-service teachers with research that fuels their imagination for what it might look like to disrupt both curriculum and instruction that fail to connect with students in ways that matter. In the context of this work, using culturally sustaining pedagogies supports students to discuss texts in ways that make sense to them by drawing on personal experiences, using linguistic and cultural knowledge, and enacting fluid identities. It also disrupts the expectation of limited and superficial contributions and connections students are often asked to make with texts. 


\section{Conclusion}

Firmly placing student's cultural and linguistic identities within a dynamic curriculum expands the goals and outcomes beyond a purely technical and procedural one, which often results in a "detachment from the human beings teachers encounter in the classroom” (Rodriguez \& Smith, 2011, p. 91). Additionally, it challenges the idea of fixed identities, particularly the identities of students of color, that may be based in conscious or unconscious stereotyping. A curriculum that embodies these pedagogies also supports personal voice and connections among students in a space (school) that often disregards, silences, or pushes to the margins their lived realities. In this way, learning is reimagined as generating knowledge that comes from opportunities that begin with student experiences as they analyze curricular tasks.

At the end of period, students were reminded to complete their homework and to make sure not to lose their coming-of-age scenarios. As the bell rang and students began leaving, one student noted, "today was a great day." We want students to have that same sensibility every day in their classes.

\section{References}

Alim, H. S. (2007). "The whig party don't exist in my hood”: Knowledge, reality, and education in the Hip Hop Nation. In H. S. Alim \& J. Baugh (Eds.), Talking Black Talk: Language, Education, and Social Change (pp. 15-29). New York, NY: Teachers College Press.

Alim, H. S. (2011). Hip Hop and the politics of ill-literacy. A Companion to the Anthropology of Education, 35(2011), 232-246.

Anyon, J. 1980. Social class and the hidden curriculum of work. Journal of Education 162:67-92.

Bean, T. W., \& Moni, K. (2003). Developing Students' Critical Literacy: Exploring Identity Construction in Young Adult Fiction. Journal of Adolescent \& Adult Literacy, 638-648.

Bloome, D., Carter, S. P., Christian, B. M., Otto, S., \& Shuart-Faris, N. (2005). Discourse analysis and the study of classroom language and literacy events: A microethnographic perspective. New Jersey: Lawrence Elbaum Associates.

Brown, A. (2005). Using hip-hop in schools: Are we appreciating culture or raping rap. The Council Chronicle.

Cammarota, J. (2007). A social justice approach to achievement: Guiding Latina/o students toward educational attainment with a challenging, socially relevant curriculum. Equity \& Excellence in Education, 40(1), 87-96.

Campano, G. (2007). Immigrant students and literacy: Reading, writing, and remembering. New York: Teachers College Press.

Crenshaw, K. (1989). Demarginalizing the intersection of race and sex: A black feminist critique of antidiscrimination doctrine, feminist theory and antiracist politics. U. Chi. Legal F., 139.

Delgado Bernal, D., Burciaga, R., \& Flores Carmona, J. (2012). Chicana/Latina testimonios: Mapping the methodological, pedagogical, and political. Equity \& excellence in education, 45(3), 363-372.

Delgado, R., \& Stefancic, J. (Eds.). (1997). Critical white studies: Looking behind the mirror. Temple University Press.

DiGiacomo, D. K., \& Gutiérrez, K. D. (2017). Seven chilis: Making visible the complexities in leveraging cultural repertories of practice in a designed teaching and learning environment. Pedagogies: An International Journal, 12(1), 41-57.

Dutro, E. (2008). "That's why I was crying on this book": Trauma as testimony in responses to literature. Changing English, 15(4), 423-434.

Dutro, E., \& Zenkov, K. (2008). Urban students testifying to their own stories: Talking back to deficit perspectives. In 57th yearbook of the National Reading Conference (pp. 172-218). Oak Creek, WI: National Reading Conference, Inc.

Dyches, J. (2017). Shaking off Shakespeare: A White teacher, urban students, and the mediating powers of a canonical counter-curriculum. The Urban Review, 49(2), 300-325.

Dyches, J., \& Sams, B. L. (2018). Reconciling Competing Missions of English Education: A Story of Pedagogical Realism. Changing English, 1-14.

Dyson, A. H. (2008). Staying in the (curricular) lines: Practice constraints and possibilities in childhood writing. Written Communication, 25(1), 119-159.

Fecho, B., \& Botzakis, S. (2007). Feasts of becoming: Imagining classroom based on dialogic literacy beliefs. Journal of Adolescent \& Adult Literacy, 50(7), 548-558.

Fine, M. (1987). Language Arts. National Council of Teachers of English, 64(2), 157-174. 
Gay, G. (2000). Culturally responsive teaching: Theory, research, and practice. New York: Teachers College Press.

Gee, J. P. (1999). Critical issues: Reading and the New Literacy Studies: Reframing the National Academy of Sciences report on reading. Journal of Literacy Research, 31(3), 355-374.

Gee, J. P. (2015). Social linguistics and literacies: Ideology in discourses (fifth). New York, NY: Routledge.

González, N., Moll, L. C., \& Amanti, C. (Eds.). (2006). Funds of knowledge: Theorizing practices in households, communities, and classrooms. New York, NY: Routledge.

Gutiérrez, K. D., Larson, J., \& Kreuter, B. (1995). Cultural Tensions in the scripted classroom: The value of the subjugated perspective. Urban Education, 29(4), 410-442. http://doi.org/10.1017/CBO9781107415324. 004.

Gutiérrez, K. D., \& Rogoff, B. (2003). Cultural ways of learning: Individual traits or repertoires of practice. Educational Researcher, 32(5), 19-25.

Hall, T. (2011). Designing from their own social worlds: The digital story of three African American young women. English Teaching, 10(1), 7-20.

Hamel , F. L. \& Smith, M. W. (1998). You Can’t Play If You Don’t Know the Rules: Interpretive Conventions and the Teaching of Literature to Students in Lower-Track Classes, Reading and Writing Quarterly: Overcoming Learning Difficulties, 14(4), 355-77.

Heath, S. B. (1983). Ways with words. Cambridge, UK: Cambridge University Press.

Irizarry, J. G. (2007). Ethnic and urban intersections in the classroom: Latino students, hybrid identities, and Culturally Responsive Pedagogy. Multicultural Perspectives, 9(3), 21-28.

Jabal, E., \& Rivière, D. (2007). Student identities and/in schooling: Subjection and adolescent performativity. Discourse: Studies in the Cultural Politics of Education, 28(2), 197-217.

Jones, S. (2004). Living poverty and literacy learning: Sanctioning topics of students' lives. Language Arts, 81(6), 461-469.

Kirkland, D. E. (2008). "The rose that grew from concrete": Postmodern Blackness and new English education. The English Journal, 97(5), 69-75.

Kirkland, D. E. (2011). Books like clothes: Engaging young black men with reading. Journal of Adolescent and Adult Literacy, 55(3), 199-208.

Ladson-Billings, G. (1994). The dreamkeepers: Successful teachers of Black children. San Francisco, CA: Jossey-Bass.

Ladson-Billings, G. (1995). Toward a theory of culturally relevant pedagogy. American Educational Research Journal, 32(3), 465-491.

Leander, K. M. (2002). Locating Latanya: The situated production of identity. Research in the Teaching of English, 37(2), 198-250.

Lee, C. D. (2007). Culture, literacy, and learning: Taking bloom in the midst of the whirlwind. New York, NY: Teachers College Press.

McCarthey, S. J. (2001). Identity construction in elementary readers and writers. Reading research quarterly, 36(2), 122-151.

McCarty, T. L., Romero, M. E., \& Zepeda, O. (2006). Reclaiming the gift: Indigenous youth counter-narratives on native language loss and revitalization. The American Indian Quarterly, 30(1/2), 28-48.

Moje, E. B., Overby, M., Tysvaer, N., \& Morris, K. (2008). NIH Public Access. Harvard Educational Review, 78(1), 107-154.

Moll, L. C. (1992). Literacy research in community and classrooms: A sociocultural approach. Multidisciplinary Perspectives on Literacy Research, 211-244.

Moll, L., Amanti, C, Neff, D., Gonzalez, N. (1992). Funds of knowledge for teaching: Using a qualitative approach to connect homes and classrooms. Theroy Into Practice 31(2), 132-141.

Noguera, P. A. (2003). Schools, prisons, and social implications of punishment: Rethinking disciplinary practices. Theory Into Practice, 42(4), 341-350.

Paris, D., \& Alim, H. S. (2014). What are we seeking to sustain through culturally sustaining pedagogy? A loving critique forward. Harvard Educational Review, 84(1), 85-100.

Paris, D. (2012). Culturally sustaining pedagogy: A needed change in stance, terminology, and practice. Educational Researcher, 41(3), 93-97.

Rex, L. A. (2006). Acting “cool” and "appropriate”: Toward a framework for considering literacy classroom interactions when race is a factor. Journal of Literacy Research, 38(3), 275-325.

Robinson, J.G. (2007). Presence and persistence: Poverty ideology and inner-city teaching. Urban Review, 39, 541-565.

Rodriguez, A., \& Smith, M. D. (2011). Reimagining Freirean pedagogy: Sendero for teacher education. Journal for Critical Education Policy Studies, 9, 91-103.

Smitherman, G. (2004). Language and African Americans: Movin on up a lil higher. Journal of English Linguistics, 32(3), 186-196. 
Solórzano, D. G., \& Yosso, T. J. (2002). Critical race methodology: Counter-storytelling as an analytical framework for education research. Qualitative inquiry, 8(1), 23-44.

Sosa, T. (2017). Recently I was in a fatal incident: Personal narratives and social identities. Linguistics and Education, 42, 34-42.

Strauss, A. (1978). A social world perspective. Studies in Symbolic Interactionism, 1, 119-128.

Thomas, E. E. (2015). " We Always Talk About Race": Navigating Race Talk Dilemmas in the Teaching of Literature. Research in the Teaching of English, 50(2), 154.

Thomas, E. E., \& Stornaiuolo, A. (2016). Restorying the self: Bending toward textual justice. Harvard Educational Review, 86(3), 313-338.

Valenzuela, A. (1999). Subtractive schooling: U.S.-Mexican youth and the politics of caring. Albany, NY: State University of New York Press.

Yosso, T. J. (2005). Whose culture has capital? A critical race theory discussion of community cultural wealth. Race Ethnicity and Education, 8(1), 69-91.

\section{幆}

